\title{
Predicting Building Energy Consumption using Engineering and Data Driven Approaches: A Review
}

\author{
Aulon Shabani, and Orion Zavalani
}

\begin{abstract}
Rapid growth of world population has higher impact on increasing buildings energy consumption. Therefore, improving energy consumption is an important concern for building engineers and operators. Energy management through forecasting approaches as one of most effective methods is in focus of this paper. Review of most elaborated methods is in our focus, where we investigate two main directions of energy prediction approaches. First category of approaches focuses on engineering methods mainly very reliable on building early operation stages and design phase, meanwhile second category go through data driven methods. Existing research works focused on these two models are introduced emphasizing advantages and relevant applications of methods.
\end{abstract}

Index Terms-Artificial Intelligence; Building; Energy Consumption; Engineering Methods; Prediction.

\section{INTRODUCTION}

Last decades building energy consumption has increased significantly. Particularly in EU and North America, counting 1.5-2 \% increase per annum and higher rates in China and developing countries. One third of total energy is consumed in buildings; moreover, in USA [1] buildings count $75 \%$ of total electricity consumption as shown in Error! Reference source not found.. Improving building energy efficiency is a growing concern worldwide.

In Albania, residential, public and commercial buildings occupy $76 \%$ of the total electricity consumption of the country. Zavalani and Luga underline in [2] that public facilities in Albania result with great electrical energy losses and do not fulfill the National Energy Building Code.

Two are major phases that crucially energy efficiency can be improved [3]. Firstly, design phase when architects and designers try to find and avoid as much as possible key contributing factors in consumption, secondly operation and control as the most important, and long-lasting phase when improvement of energy efficiency is significant.

One of the most developed methods in literature improving energy efficiency is predicting energy demand for next hours. That gives the opportunity to building operators and engineers to control ahead in time energy consumption without intervening in human comfort; on the other hand, it is very important to reduce peak load one of the greatest concerns in electrical grid.

Different predictive methods have been developed, mainly divided in two categories: model based methods (engineering

Published on May 22, 2017.

A. Shabani. is with the Departments of Electrotechics, Faculty of Electrical Engineering, Polytechnic University of Tirana, Sheshi "Nënë Tereza", Nr.4, Tiranë, Albania (e-mail: aulon.shabani@ fie.upt.al).

O. Zavalani. is with the Department of Automation, Faculty of Electrical Engineering, Polytechnic University of Tirana, Sheshi "Nënë Tereza", Nr.4, Tiranë, Albania (e-mail: orion.zavalani@ fie.upt.al). methods) and data driven methods (statistical and machine learning methods).

This paper reviews most used engineering approaches following in section II, and then by data driven approaches in section III. General overview of advantages and disadvantages of two main directions are discussed in section IV, finalizing the paper in section V.

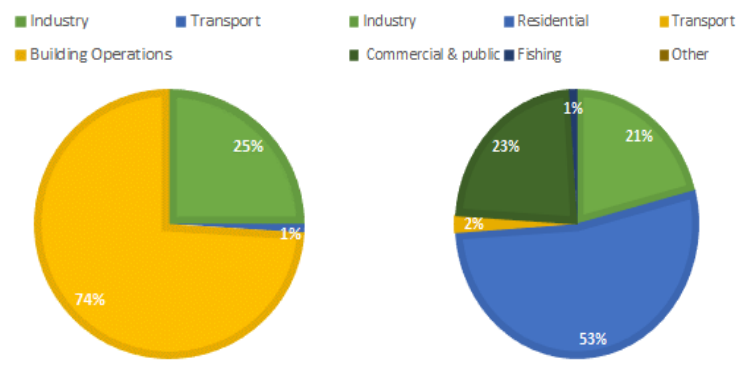

Fig.1. USA electricity consumption by sector [1] left figure, Albania electricity consumption right.

\section{BUILDING ENERGy PREDICTION APPROACHES}

Comprehensive engineering approaches are mathematical models of buildings, which take in consideration physical proprieties of construction materials to create building thermal envelopes. Usually they are used to calculate building dynamic behavior, for whole building or even for sub-level components like heating, cooling, electricity demand and other required parameters. This approach models building physical proprieties to an RC electrical circuit, which roughly can be classified as simple thermal circuit or detailed modelling circuit.

The inputs have a variety starting from environmental information like outside air temperature and humidity, solar radiation, building construction information, building operation, sub-level components functionality, control systems, building geographical positioning and other relevant information used as inputs to predict step by step energy consumption. In our focus are applications of these models to building energy demand not detailed technical information regarding use of mathematical methods.

Lam and Hui [4] use building simulation software (DOE2) to analyze building electricity consumption in terms of sensitivity analysis. They analyze annual building energy consumption, peak design loads and profiles of electrical demand and cooling by taking in account parameters for 
modeling such as building load and HVAC (Heating Ventilation and Air Conditioning) systems. Concluding with capabilities of sensitivity analysis gives to designers regarding thermal design, data analysis and preliminarily energy estimates. Yik et al. [5] analyze in large-scale study energy consumption of 23 office and 16 hotel buildings in Hong Kong. The study takes in account the impact of different heating and cooling systems in total, yearly energy consumption. The paper also presents computer simulation programs possibilities of predicting cooling load, electricity consumption and air conditioning systems.

Crawley [6] describe the possibilities created by the new simulation framework EnergyPlus, which is a combination of features from DOE-2 and BLAST used to predict hourly building energy consumption. Likewise, Sousa [7] conduct a review comparing capabilities of energy prediction methods, also explaining crucial steps needed to apply these methods.

Table 1 shows most used simulation tools used to analyze and predict energy in buildings.

TABLE I: OVERVIEW OF BUILDING ENERGY ANALYSIS TOOLS [8, 9].

\begin{tabular}{|c|c|c|}
\hline Soft & Advantages & Drawbacks \\
\hline 禹 & $\begin{array}{l}\text { - hourly modelling to predict energy } \\
\text { consumption of space load, air } \\
\text { system and central plant, } \\
\text { - analyzes energy performance of } \\
\text { new and old buildings. }\end{array}$ & $\begin{array}{l}\text { - does not use air } \\
\text { humidity, } \\
\text { - not user specified } \\
\text { constrains. }\end{array}$ \\
\hline ๙ั่ & $\begin{array}{l}\text { - detailed, hourly, } \\
\text { - whole-building energy analysis of } \\
\text { multiple zones in buildings of } \\
\text { complex design; } \\
\text { - widely recognized as the industry } \\
\text { standard; } \\
\text { - residential and commercial } \\
\text { buildings. }\end{array}$ & $\begin{array}{l}\text { - not very user } \\
\text { friendly, } \\
\text { - expert knowledge } \\
\text { required }\end{array}$ \\
\hline 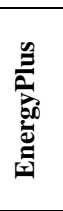 & $\begin{array}{l}\text { - detailed simulation frequency less } \\
\text { than an hour, } \\
\text { - interfacing with CAD, } \\
\text { - input and output data structures } \\
\text { tailored to facilitate third party } \\
\text { interface development free. }\end{array}$ & $\begin{array}{l}\text { - text input difficult } \\
\text { to use compared to } \\
\text { graphical interfaces. }\end{array}$ \\
\hline 氛 & $\begin{array}{l}\text { - easy to use, } \\
\text { - detailed simulation with hourly } \\
\text { frequency, } \\
\text { - uses information about occupancy, } \\
\text { seasonal variables and construction } \\
\text { characteristics such as walls, } \\
\text { windows, thermal mass etc... } \\
\text { - offers energy cost estimating, } \\
\text { daylighting and lighting system } \\
\text { control, } \\
\text { - free to use. }\end{array}$ & $\begin{array}{l}\text { - does not offer } \\
\text { thermal comfort } \\
\text { estimation, } \\
\text { - unavailable } \\
\text { exporting geometry. }\end{array}$ \\
\hline 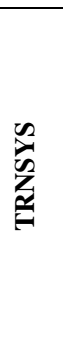 & $\begin{array}{l}\text { - modular structure, } \\
\text { - models simple components and } \\
\text { complex, } \\
\text { - facilities with visual interface, } \\
\text { - models photovoltaic systems, low } \\
\text { energy buildings, HVAC systems } \\
\text { - offers the ability of adding new } \\
\text { mathematical models, } \\
\text { - unlimited of user specified } \\
\text { constrains. }\end{array}$ & $\begin{array}{l}\text { - does not use } \\
\text { seasonal variables, } \\
\text { - not convertible to } \\
\text { other simulation } \\
\text { software's. }\end{array}$ \\
\hline
\end{tabular}

A detailed review emphasizing advantages and disadvantages for larger amount of methods the reader can referred to [8]. Detailed overview of building simulation programs for energy analysis is in focus of Hong [10], where they emphasize the capabilities of each single software, what kind of resource information to be used. The research provides useful information for building operators, designers and engineers to approach simulation software's more effectively. Likewise, Al Hamoud [11] give an overview of available building energy analysis available, giving concepts of simple steady state methods to detailed and complex hourly models. Their approach tends to give experts a powerful tool for implementing accurate and user-friendly building energy models. Dos Santos and Mendez [12] apply a mathematical model to analyze the energetic behavior of buildings, based on lumped capacitive circuit. Comparison of time steps to compute different numerical methods was in focus of the study using finite difference method as main method. A new method EPW (Energie Prestatie Wetgeving), which predicts net energy consumption, was compared to traditional methods TRNSYS and ESP-r, and the results are very promising according to authors in [13]. Combining neural networks with mathematical models Olofsson and Andersson [14] evaluate heating losses in residential buildings using artificially generated data. Differently Lunding [15] estimate heating loss coefficient using real measured data gained from temperature difference. Combining lumped capacitance circuit with artificial neural networks, they obtain desired results regarding gain factor, total heat capacity and total heat loss coefficient. Based on EnergyPlus models Fumo [16] analyze building energy consumption based on monthly electricity use and fuel bills. Low consumption energy buildings are also in focus of authors in [17]. They predict heating demand using weather predictions as inputs for building thermal models.

In [18] authors conduct a research with focus HVAC systems based on simulation programs. Most used frameworks are compared taking in account component models, HVAC system control, control strategies and emphasizing inputs used for each of the models. Model based control strategies used to improve energy prediction and use are published in [19], where a control-oriented modelling strategy is used. Likewise, Date [20] use control oriented strategy to improve house thermal modelling from multilevel point of view. Based on simple RC thermal model to calculate thermal load in several zones. Amara [21] conduct a review comparing existing subfields for energy prediction. Contrasting 'white box' (physical) models with 'black box' (statistical), they emphasize strong and weak points of each model. They also conclude that 'grey box' models a combination of two other approaches can be the leading method regarding energy prediction in near future. Authors report reducing energy consumption of office building using lumped capacitance modelling in [22], where model predictive control improves energy efficiency using results obtained from short-term predictions. Results improve by $43 \%$ total energy consumption compared to traditional control systems.

\section{DATA DRIVEN APPROACHES}

We devote this section to describe traditional machine learning (ML) and recent methods used to predict building energy consumption. Machine learning methods fit model or pattern, from given input examples to desired targets, and the learned rule predicts new outputs for given new (unseen) examples. There exist various ML algorithms addressing problem of energy prediction in buildings. As state of art 
methods, we can mention artificial neural networks (ANNs) and support vector regression (SVR). Recently other ML methods applied in the domain, argue their advantages over traditional methods. Regression trees (RT) and case base reasoning (CBR) have put forward their applicability to the domain.

\section{A. Artificial neural networks}

Energy consumption has a complex nonlinear behavior, strongly related to outdoor climatic factors. Since ANNs have a strong ability dealing with nonlinear problems, make them the most used approach to predict energy demand in buildings. ANNs applications at most consists in analysis of building energetic behavior, predicting building energy consumption, predicting HVAC systems and sub-level components energy consumption. We briefly describe application framework of neural networks to building energy consumption.

Azadeh [23] predict long-term energy consumption in high industrial consumers by training a multi-layer perceptron using long-term data available from Iran industrial consumers. They contrast the capabilities of ANNs with regard to statistical approaches as ANOVA. Wong [24] analyze building behavior and predict office energy demand in subtropical region due to daylight and climacteric conditions using an ANN. Model uses as inputs variables related to outside weather conditions, building physical proprieties and a weekday indicator. Combining and comparing computer-aided simulations with data driven approaches, they show the priority ANN method.

Kalogirou [25] to predict heating load of passive solar building uses dynamic thermal modeling in combination with back propagation neural networks.

Likewise, Yokoyama in [26] use a back propagation ANN to predict cooling energy demand. Preventing drawbacks of local optimization methods, they implement a global optimization method called "Modal Trimming" to optimize ANN parameters.

Cooling demand of buildings is also in focus of Ben-Nakhi and Mahmoud in [27], where they use a general regression ANN. The network performance was evaluated with data generated from building simulation software ESP-r, where three-year of 24-hour measurements used as training and one year was used as testing. Back propagation ANNs used by Cheng-wen and Ying [28] to predict heating and cooling demand are using building envelope performance in combination with heating degree day HDD and cooling degree day CDD as training input parameters. They emphasize the importance of training such models to predict energy consumption in early design stages, and achieve accurate results.

Gonzales and Zamarreno [29] predict hourly electricity consumption in buildings using a recurrent neural network. Simple model implemented using real observed data achieves significantly accurate results, where forecasted air temperature and current load are the input attributes. $\mathrm{Li}$ [30] compare traditional ANNs with hybrid genetic algorithmadaptive network-based fuzzy inference system (GAANFIS), where GA is used to find best parameters and the ANFIS adjust the parameters to match training data. Predicted energy consumption estimated by GA-ANFIS shows higher accuracy in terms of coefficient of variation $(\mathrm{CV})$. Olofsson [31] use neural networks to predict space heating demand when limited number of performance parameters are available. They propose a quasi-physical approach to describe building performance based on outdoor and indoor temperatures and other simple parameters.

A study how statistical methods can improve ANNs performance in hourly energy prediction is in focus of Karatasou [32], also they implement on real data combination of ANN with statistical approaches to gain highly desirable results. Neural networks are one of the most used approaches applied to predict energy consumption in buildings, as matter of fact Kalogirou [33] give a brief review application of ANN methods with regard to building energy consumption.

\section{B. Support vector regression}

Support vector Machines (SVMs) as one of the most used and successive methods in machine learning, with strong ability of solving non-linear regression problems (SVR), recently has become very popular predicting energy demand in buildings.

Application of SVMs to predict energy consumption in buildings start with Dong [34], where four buildings in tropical region having four years historical data, were selected as targets to predict consumption, using three weather features and monthly average energy consumption. Results gained from trained models in three years and tested in one-year data show significant better results of SVMs to predict monthly utility bills.

Lai [35] use SVMs to predict residential buildings electricity consumption based on one-year recordings, including electricity and climatic data such as temperature and humidity. They are searching to implement an automated energy predictor model based mostly on SVM and other relevant signal processing and data preprocessing approaches.

Li [36] predict cooling energy consumption of a commercial building using SVMs. Comparison with different ANN models, points out that SVMs and GRNN have higher accuracy than the other models. Same authors in [37] use SVMs to predict hourly building cooling demand.

In [38] authors apply SVMs to predict next day electricity load, where 24 individual regression methods each of them corresponding to hour of the day are trained to predict hourly energy consumption, aggregation of individual models prove that SVM models performance is significantly higher compared to other ML methods as ANNs, statistical methods and regression trees.

Zhao and Magoulès [39] predict energy consumption with SVMs using large-scale datasets. Improving speed of training process, they use parallel SVM emphasizing advantages of the model especially for large and complex datasets.

Improving building energy performance SVMs are combined with other relevant methods. Like in [40] authors use kernel principal analysis (KPCA) as feature extraction method and SVM are used as regression method for predicting building cooling demand. In addition, authors in [41] use SVMs to predict cooling load demand, where combination of SVM and fuzzy C-mean clustering improves the prediction performance.

Although applying SVM methods highly important are 
support vector hyper-parameters, where Pai and Hong [42] use recurrent SVM to predict electricity consumption, and genetic algorithms (GA) are used to define the hyperparameters.

\section{Regression trees}

Decision Trees (DT) a well-known ML method for classification and regression (RT), recently used to predict energy demand in buildings shows competitive results compared to other traditional methods as ANNs and SVMs.

Yang and Stenzel in [43] predict short-term load of energy grid system in Shanghai using a hybrid approach of incremental RT in combination with SVM and compare the results to pure non-incremental RT. Results achieved show the superiority of implemented hybrid approach to predict accurately energy consumption.

Tso and Yau in [44] apply data driven approaches to predict energy consumption in building based on different features, where model selection procedure applied refers to squared root error. Comparing RT with ANNs and linear regression methods, RT results as the model with fewer inputs used and during summer phase, they outperform other models instead of winter phase slightly losing against ANNs.

Authors in [45] use RT to generate predictive energy demand models. The method has higher performance in classifying energy consumption influential factors and is very helpful deriving information from measured data.

\section{Case based reasoning}

Recently as an alternative prediction method, case based reasoning (CBR) has been put forward with the purpose of predicting energy demand in buildings. CBR is an instance based data driven approach, differently from three others approaches mentioned above which are model based methods.

Monfet in [46] develop a CBR tool for predicting energy consumption in buildings. Implemented model used real monitored data observed from office building in Canada. Results achieved have better performance during building operation than whole day prediction. Prediction accuracy measured in terms of CV-RMSE (coefficient of variation of root mean squared error) is within limits recommended by ASHRAE $^{1}$ [47].

Likewise, Platon in [48] implement a CBR model to predict energy consumption for a Canadian institutional building using prediction horizon of 6 hours. They implement a feature selection method like PCA to improve model accuracy, and achieved results compared to ANNs show the ability of CBR approaches to be used in the domain. The same author in [49] implements an on-line model of CBR, emphasizing the easiness of such approaches to be used in online fashion. Results achieved improve their performance due to increasing amount of data available to learn.

An improved CBR model of [48] is developed by Shabani [50], they show the effectiveness of CBR model to perform better than ANNs in scenarios when few available data are available in learning phase. In addition, implementation of online learning CBR performs very well compared to "offline" learning. CBR publications implemented to predict building energy consumption have an increasing amount recently.

TABLE II: COMPARISON OF METHODS MAIN CHARACTERISTICS DESCRIBED FOR BUILDING ENERGY PREDICTION

\begin{tabular}{|c|c|c|c|c|}
\hline Method & Complexity of model & User friendly & Features used & Performance \\
\hline Simple engineering & High & Yes & Simple physical & High \\
\hline Complex engineering & Fairly high & No & Complex physical & Fairly high \\
\hline ANNs & High & No & Historical data & High \\
\hline SVMs & Fairly high & No & Historical data & Fairly high \\
\hline RT & Fair & Yes & Historical data & High \\
\hline CBR & Fair & Yes & Historical data & Fair \\
\hline
\end{tabular}

\section{Discussion}

Analysis of building energy consumption approaches described above emphasize that a large amount of information is needed to apply both engineering and data driven approaches. Each of the models has its own requirements regarding the information in order to apply it correctly.

Engineering methods need relevant information about building physical proprieties and also some of the approaches use secondary information like occupancy and building functionality. They are very useful especially in design phase, early stages of operation and in cases when renovations or modifications are made. Requiring a large amount of expert knowledge and the decreasing ability to predict accurately after a long operation time due to the fact of building amortization (material physical proprieties change) are some of main disadvantages of these models.

Data driven approaches have strong abilities to solve non- linear problems, as it is building energy consumption. Recently they have put forward a large contribution to energy prediction problems. Data driven approaches reviewed in this paper like in every regression problem in machine learning can be classified in two categories: model based approaches (ANNs, SVMs, RT) and instance based approaches like CBR. ANNs as one of the oldest methods used to predict energy consumption give very accurate results using moderate complicated structure. In addition SVMs give more accurate results, but using more complicated structure and more parameters to define. Recently the idea of applying regression trees a simpler model compared with two other abovementioned approaches gives comparable results. Instance based approaches like CBR have advantages over model based approaches the easiness of user to understand what happens behind, but their results do not perform better than model based. According to [50] in case of data sparsity CBR perform slightly better than ANNs. Data driven approaches require considerable amount of historical data and have

\footnotetext{
1 American Society of Heating, Refrigerating and Air-Conditioning Engineers
} 
complexity in application. Rough summary of advantages and disadvantages related to energy prediction methods are shown in Table II.

\section{CONCLUSIONS}

This paper reviews two main existing approaches used to predict energy consumption in buildings. Engineering methods as one of most used technique and data driven methods as the uprising used methods help to improve control techniques and energy efficiency. Because building energy consumption is aggregation of many influencing factors, it is not easy to emphasize which is the best approach to use, but we try to bring advantages and disadvantages of applied techniques.

Engineering methods are very efficient tool to use in design phase or early stages of operation on the other hand, data driven approaches are very useful and accurate because they deal with nonlinear problems and can be modelled easily by taking in account many influential factors. Data driven approaches are restricted to the existence of past-observed measurements, but at that point, engineering methods are applicable. Instead engineering methods request a lot of expert knowledge and a lot of effort in building modelling which is not so necessary to data driven approaches.

Except traditional and most used data driven models like ANNs and SVMs we describe also two recently used approaches like RT and CBR.

In the future, we tend to extend this work by evaluating empirically data driven approaches on synthetic datasets generated by engineering methods, and including online prediction approaches, which are not very used so far.

\section{REFERENCES}

[1] IEA, "World energy outlook 2015. International Energy Agency; September 2015".

[2] O. Zavalani and Y. Luga, "Energy and Water Saving Possibilities in Public Facilities in Albania," in Fourth UKSim European Symposium on Computer Modeling and Simulation (EMS), Pisa, Italy, 2010.

[3] O. Zavalani, "Reducing energy in buildings by using energy management systems andalternative energy-saving systems," in 8th InternationalConference on the European Energy Market (EEM-11), Zagreb, 2011.

[4] J. C. Lam and S. C. Hui, "Sensitivity Analysis of Energy Performance of Office Buildings," Building and Environment, vol. 31, no. 1, pp. 27 39, 1996.

[5] F. Yik, J. Burnett and I. Prescott, "Predicting air-conditioning energy consumption of a group of buildings using different heat rejection methods," Energy and Buildings, vol. 33, pp. 151-166, 2001.

[6] D. B. Crawley, L. K. Lawrie, F. C. Winkelmann, W. F. Buhl, J. Y. Huang, C. O. Pedersen, R. K. Strand, R. J. Liesen, D. E. Fisher, M. J. Witte and J. Glazer, "EnergyPlus : creating a new-generation building energy simulation program," Energy and Buildings, vol. 33, pp. 319331, 2001.

[7] J. Sousa, "Energy Simulation Software for Buildings: Review and Comparison," in International Workshop on Information Technology for Energy Applicatons-IT4Energy, Lisabon, 2012.

[8] D. B. Crawley, J. W. Hand, M. Kummert and B. T. Griffith, "Contrasting the capabilities of building energy performance simulation programs," Building and Envinronment, vol. 43, pp. 661 673, 2008.

[9] "http://www.eere.energy.gov/buildings/tools_directory/," Department of Energy Building Tools Directory.

[10] T. Hong, S. K. Chou and T. Y. Bong, "Building simulation: an overview of developments and information sources," Building and environment, vol. 35, pp. 347-361, 2000.

[11] M. S. Al-homoud, "Computer-aided building energy analysis techniques," Building and Environment, vol. 36, pp. 421-433, 2001.

[12] G. H. Dos Santos and N. Mendes, "Analysis of numerical methods and simulation time step effects on the prediction of building thermal performance," Applied Thermal Engineering, vol. 24, no. 8-9, pp. 1129-1142, 2004.

[13] J. Van der Veken, D. Saelens, G. Verbeeck and H. Hens, "Comparison of Steady-State and Dynamic Building Energy Simulation Programs," in Performance of Exterior Envelopes of Whole Buildings IX, Atlanta, 2004.

[14] T. Olofsson and S. Andersson, "Overall heat loss coefficient and domestic energy gain factor for single-family buildings," Building and Environment, vol. 37, pp. 1019-1026, 2002.

[15] M. Lundin, S. Andersson and R. Östin, "Development and validation of a method aimed at estimating building performance parameters," Energy and Buildings, vol. 36, pp. 905-914, 2004.

[16] N. Fumo, P. Mago and R. Luck, "Methodology to estimate building energy consumption using EnergyPlus Benchmark Models," Energy and Buildings, vol. 42, no. 12, pp. 2331-2337, 2010.

[17] J. Široký, F. Oldewurtel, J. Cigler and S. Prívara, "Experimental analysis of model predictive control for an energy efficient building heating system," Applied Energy, vol. 88, no. 9, pp. 3079-3087, 2011.

[18] X. Zhou, T. Hong and D. Yan, "Comparison of Building Energy Modeling Programs: HVAC Systems," ERNEST ORLANDO LAWRENCE BERKELEY NATIONAL LABORATORY, 2013.

[19] J. Candanedo, V. Dehkordi and P. Lopez, "A control-oriented simplified building modelling strategy," in Conference of International Building Performance Simulation Association, Chambery, France, 2013.

[20] J. Date, J. A. Candanedo and A. K. Athienitis, "Control-Oriented Modelling of Thermal Zones in a House: A Multi-Level Approach," in International High Performance Buildings Conference, Purdue, 2016.

[21] F. Amara, K. Agbossou, A. Cardenas, Y. Dubé and S. Kelouwani, "Comparison and Simulation of Building Thermal Models for Effective Energy Management," Smart Grid and Renewable Energy, vol. 6, pp. 95-112, 2015

[22] S. Sayadi, G. Tsatsaronis and T. Morosuk, "Reducing the Energy Consumption of HVAC Systems in Buildings by Using Model Predictive Control," in CLIMA 2016 - proceedings of the 12th REHVA World Congress, Heiselberg, 2016.

[23] A. Azadeh, S. Ghaderi and S. Sohrabkhani, "Annual electricity consumption forecasting by neural network in high energy consuming industrial sectors," Energy Conversion and Management, vol. 49, no. (8), pp. 2272 -- 2278, 2008.

[24] S. L. Wong, K. K. Wan and T. N. Lam, "Artificial neural networks for energy analysis of office buildings with daylighting," Applied Energy, vol. 87 , no. 2 , pp. 551-557, 2010.

[25] S. Kalogirou and M. Bojic, "Artificial neural networks for the prediction of the energy consumption of a passive solar building," Energy, vol. 25, no. (5), pp. 479 -- 491.

[26] R. Yokoyama, T. Wakui and R. Satake, "Prediction of energy demands using neural network with model identification by global," Energy Conversion and Management, vol. 50, no. 2, pp. 319-327, 2009.

[27] A. Ben-Nakhi and M. Mahmoud, "Cooling load prediction for buildings using general regression neural networks," Energy Conversion and Management, vol. 45, no. 13-14, pp. 2127 -2141, 2004.

[28] Y. Cheng-wen and Y. Jian, "Application of ann for the prediction of building energy consumption at different climate zones with hdd and cdd," in 2nd International Conference on Future Computer and Communication, 2010.

[29] P. González and J. Zamarreño, "Prediction of hourly energy consumption in buildings based on a feedback artificial neura network," Energy and Buildings, vol. 37, no. (6), pp. 595 -- 601, 2005.

[30] L. Kangji , S. Hongye and C. Jian , "Forecasting building energy consumption using neural networks and hybrid neuro-fuzzy system: A comparative study," Energy and Buildings, vol. 43, no. 10, p. 2893 2899, 2011.

[31] T. Olofsson, S. Andersson and R. Östin, "A method for predicting the annual building heating demand based on limited performance data," Energy and Buildings, vol. 28, no. 1, pp. 101-108, 1998.

[32] S. Karatasou, M. Santamouris and V. Geros, "Modeling and predicting building's energy use with artificial neural networks: Methods and results," Energy and Buildings, vol. 38, no. 8, pp. 949-958, 2006.

[33] S. Kalogirou, "Artificial neural networks in energy applications in buildings," International Journal of Low-Carbon Technologies, vol. 1, no. 3, pp. 201-216, 2006

[34] B. Dong, C. Cao and S. E. Lee, "Applying support vector machines to predict building energy consumption in tropical region," Energy and Buildings, vol. 37, no. 5, pp. 545-553, 2005.

[35] F. Lai, F. Magoules and F. Lherminier, "Vapnik's learning theory applied to energy consumption forecasts in residential buildings," International Journal of Computer Mathematics, vol. 85, no. 10, pp 1563-1588, 2008. 
[36] Q. Li, Q. Meng, J. Cai, H. Yoshino and A. Mochida, "Predicting hourly cooling load in the building: A comparison of support vector machine and different artificial neural networks," Energy Conversion and Management, vol. 5, no. 1, pp. 90-96, 2009.

[37] Q. LI, Q. Meng, J. Cai, H. Yoshin and A. Mochida, "Applying support vector machine to predict hourly cooling load in the building," Applied Energy, vol. 86, no. 10, pp. 2249-2256, 2009.

[38] Y. Fu, Z. Li, H. Zhang and P. Xu, "Using support vector machine to predict next day electricity load of public buildings with sub-metering devices," Procedia Engineering, vol. 121, pp. 1016-1022, 2015.

[39] H. X. Zhao and F. Magoulès, "Parallel support vector machines applied to the prediction of multiple buildings energy consumption," Journal of Algorithms and Computational Technology, vol. 4, no. 2, pp. 231-249, 2010.

[40] L. Xuemei, D. Lixing, L. Jinhu, X. Gang and L. Jibin, "A novel hybrid approach of kpca and svm for building cooling load prediction," in Knowledge Discovery and Data Mining, 2010. WKDD'10, 2010.

[41] L. Xuemei, D. Yuyan, D. Lixing and J. Liangzhong, "Building cooling load forecasting using fuzzy support vector machine and fuzzy c-mean clustering," in Computer and Communication Technologies in Agriculture Engineering (CCTAE), 2010.

[42] P.-F. Pai and W.-C. Hong, "Forecasting regional electricity load based on recurrent support vector machines with genetic algorithms," Electric Power Systems Research, vol. 74, no. 3, pp. 101-108, 1998.

[43] J. Yang and J. Stenzel, "Short-term load forecasting with increment regression tree," Electric Power Systems Research, vol. 76, no. 9, pp. $880-888,2006$

[44] G. K. Tso and K. K. Yau, "Predicting electricity energy consumption: A comparison of regression analysis, decision tree and neural networks," Energy, vol. 32, no. 9, pp. 1761-1768, 2007.

[45] Z. Yu, F. Haghighat, B. C. Fung and H. Yoshino, "A decision tree method for building energy demand modeling," Energy and Buildings, vol. 42, no. 10, pp. 1637-1646, 2010.

[46] D. Monfet, M. Corsi, D. Choiniere and E. Arkhipova, "Development of an energy prediction tool for commercial buildings using case-based reasoning," Energy and Buildings, vol. 81, pp. 152-160, 2014.

[47] ASHRAE, "Measurement of Energy and Demand Savings," ASHRAE, Atlanta, Georgia, Guideline 14-2002.

[48] R. Platon, V. R. Dehkordi and J. Martel, "Hourly prediction of a building's electricity consumption using case-based reasoning, artificial neural networks and principal component analysis," Energy and Buildings, vol. 92, pp. 10-18, 2015.

[49] R. Platon, J. Martel and K. Zoghlami, "CBR model for predicting a building's electricity use: On-line implementation in the absence of historical data," in 23rd International Conference on Case-Based Reasoning, Frankfurt, 2015.
[50] A. Shabani, A. Paul, R. Platon and E. Hüllermeier, "Predicting the Electricity Consumption of Buildings: An Improved CBR Approach," in International Conference on Case-Based Reasoning, Atlanta, 2016.

[51] X. Li , D. Yuyan, D. Lixing and J. Liangzhong, "Building cooling load forecasting using fuzzy support vector machine and fuzzy c-mean clustering," in Computer and Communication Technologies in Agriculture Engineering (CCTAE), 2010.

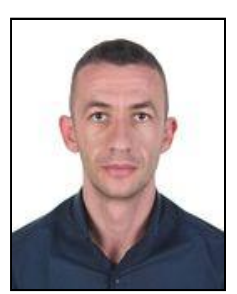

Aulon Shabani, born in 1988 received his Bachelor degree in Electrical Engineering from Polytechnic University of Tirana (Albania) in 2009 and his master degree in Electrical Engineering from same university in 2011.

Since October 2011, he is a teaching assistant in faculty of Electrical Engineering and in 2012 he is a $\mathrm{PhD}$ student under the supervision of Prof. Orion Zavalani. His main research interests include energy efficiency, in particular machine-learning applications in energy prediction.

Last two years he has been appointed as exchange $\mathrm{PhD}$ student from Euroweb+ program at Paderborn University (Germany), where he has worked in Intelligent Systems group under the supervision of Prof. Eyke Hüllermeier.

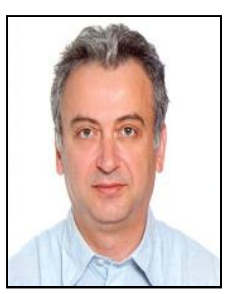

Orion Zavalani, born in 1962 received his Master degree in Electrical Engineering from Polytechnic University of Tirana (Albania) in 1987 and his PhD in Electrical Engineering from same university in 1996.

Since 1999 , he is a full professor in the faculty of Electrical Engineering with focus on designing and development of civil, commercial and industrial electrical networks, building automation systems, energy efficiency, renewable energy, low/medium voltage networks, electro-heating, standards and engineering education.

Prof. Orion Zavalani is an electrical engineer, a researcher, and an educator. He is author or co-author of more than 80 academic contributions in scientific meetings, journals and books.

$\mathrm{He}$ is member of IEEE Power \& Energy Society, IEEE Education Society and chairman of National Committee Nr.50 of Electro-technique Standards. 